\title{
Validation of Parent Proxy Report with Pedometry on Preschool Children's Physical activity 利用步行計評估幼稚園生日常活動家長記錄表的效度
}

\author{
Bik C. CHOW Yung Ching AU \\ Department of Physical Education, \\ Hong Kong Baptist University, HONG KONG
}

周碧珠歐浗晴

香港浸會大學體育學系

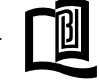

\begin{abstract}
The objective of this study was to assess the validity of the Habitual Activity Estimation Scale (HAES) as parent proxy report about the physical activity levels of five- to six-years-old children. Twenty-three children were randomly selected from upper classes in a preschool in Hong Kong. The children's physical activity levels on one typical weekday and one typical weekend were obtained by having their parents completed the HAES questionnaire. And daily steps taken by children on four consecutive days including weekdays and weekend were collected by the pedometer (Yamax, SW-700). The pedometer data were used to assess its agreement with the HAES parent proxy report of the children's physical activity levels. The results showed that the step counts of children between weekdays and weekend as well as between genders were not significantly different. The result also indicated that there was no significant correlation between the HAES proxy report and the daily step counts of children on both weekdays and weekend. To conclude, the validity of HAES parent proxy report in assessing five-years-old preschool children's physical activity levels was low when compared with pedometer data.

\section{摘要}

本研究旨在評估由家長觀察兒童使用「Habitual Activity Estimation Scale (HAES)日常活動推算表」的有效度, 邀請了 二十三名五至六歲的幼稚圍生參與作為觀察之用, 他們的父母觀察及記錄兒童於上課日和非上課日的日常活動, 並以步行計記錄 身體活動量來作分析。結果顯示： Habitual Activity Estimation Scale (HAES)和步行計的相關系數沒有出現顯著的相關, 指出 了Habitual Activity Estimation Scale (HAES)的效度不高。
\end{abstract}

\section{Introduction}

The prevalence of childhood obesity in the developed world and much of the developing world has increased dramatically in recent years (Lobstein, Baur, \& Uauy, 2004). For example, obesity of USA children ages 6-11 and ages $2-5$ is estimated to have increased from $15.1 \%$ to $18.8 \%$ and $22.0 \%$ to $26.2 \%$, respectively between 1999 and 2004 (Ogden et al., 2006). Following the world trend, there is a rising childhood obesity rate in Hong Kong. The primary students' obesity rate has increased from $16.1 \%$ in $1995-1996$ to $20.1 \%$ in $2006-2007$ (Hong Kong
Department of Health, 2009). Although no systematic survey data is available about preschool obesity, local researcher has voiced the concern for obesity problem of the Hong Kong preschool children (Chan, 2009). The obesity epidemic worldwide constitutes to a significant and growing public health problem.

On the other hand, physical activity is a well documented and recognized component of a healthy lifestyle, and childhood experiences with physical activity have an important impact on lifelong behavior. In recent years, researchers have focused on the importance of 
physical activity in preschool years (see Hinkey, Crawford, Salmon, Okely, \& Hesketh, 2008, for review) because increased physical activity in preschoolers is associated with a decrease in childhood overweight and obesity (USDHHS, 2000) and a decrease risk of having one or more risk factor for cardiovascular disease (Riddoch \& Boreham, 2000). Also increased physical activity can improve bone health and fundamental motor skill development of the children (Oliver, Schofield \& Kolt, 2007).

Research has indicated that substantial numbers of children in the UK (Armstrong \& Welsman, 1997), Europe (Gavarry et al., 2003; Riddoch et al., 2004) and the US (Pate et al., 2004, 2008) do not engage in sufficient activity during childhood to gain health benefits. When investigating PA levels of 3-5-year-olds preschool children during preschool day, Pate et al. (2008) found that children engaged in MVPA during less than $3 \%$ of the observation and were sedentary during more than $80 \%$ of the observation intervals. Furthermore, there were gender (Jackson et al., 2003; Pate et al., 2004) and age differences (Grontved et al., 2009) in PA of preschool children. In a small sample study of Hong Kong young children, Louie and Chan (2003) found that boys were more physically active than girls both by the pedometer counts $(\mathrm{F}=22.38, \mathrm{p}<0.01)$ and by observation scale. On the other hand, research findings also showed that children were more active on the weekends than weekdays. According to Hay and Cairney (2006), girls and boys had significantly more hours of activity on weekends than on weekdays due to the constraints of school. In addition, children's activity patterns on weekends were significantly different from their patterns on weekdays, children were more active on the weekends than weekdays since school days hold fewer opportunities for activity.

To understand why some children are more active than others and how to encourage them to be more active, there is a need to measure physical activity accurately and reliably. Valid methods of estimating physical activity in children are critical for understanding the dose-response relationship between physical and chronic diseases and associated risk factors. And accurate assessment of physical activity in children is necessary to identify current levels of activity and to assess the effectiveness of intervention programmes designed to increase physical activity (Sirard \& Pate, 2001).
Physical activity has traditionally been measured with surveys and recall instruments. However, recall errors may occur in self-report of young children's activity because it is difficult for young children to recall the intensity and duration of physical activity (Sirard \& Pate, 2001). Proxyreports such as the Habitual Activity Estimation Scale (HAES) have been developed to evaluate the current level of children's physical activity by having parents or caregivers to recall the duration and intensity of children's physical activity within 2-days (Sirard \& Pate, 2001). The HAES can provide accurate knowledge of physical activity levels that allows researchers to develop physical activity intervention programmes and to assess their effectiveness (Sirard \& Pate, 2001). Also, the measuring scale can be easily completed within 10 minutes which require only basic cognitive skills and the report can be easily recognized in terms of segments of time and distinct activity categories. Research has shown that the HAES scale to be a clinically useful activity measurement tool (Hay \& Cairney, 2006). The construct validity of HAES has been supported by demonstrating significant relationships with accelerometer data (Hay, Faught, Cairney, \& Wade, 2005; Molgaard, Thomsen, \& Michaelkson, 2001). Furthermore, reliability for a 2-day period of the HAES was established (Hay, Atkinson, \& Halton, 1995).

Apart from using survey to collect information about children's physical activity levels, mechanical devices such as motion sensors have been used in measuring children's physical activity. Pedometry is one of the methods that can measure all type of walking or running movement by using a pedometer which is attached to the waistband in the midline of the thigh on either side of the body. Pedometer, a step counter electrical device, has been used to measure physical activity of Hong Kong children during playtime in preschools (Chow, 2009; Louie \& Chan, 2003). Pedometer is easy to use, light in weight and is inexpensive. Yamax series models are the most accurate for use with adults. Cardon and de Bourdeaudhuij (2007) provided convergent validity of the Yamax SW-200 in 76 children aged $4-5.9$ years. A significant correlation $(\mathrm{r}=0.73)$ was found between total daily steps and minutes of MVPA assessed using the MTI 7164 ActiGraph. Hands, Parker and Larkin (2006) found that the pedometer is a valid measure of physical activity in young children when engaged in a variety of free play activities as compared to the accelerometer. In a review of the measurement issues of pedometers, Oliver, Schofield, and Kolt (2007) concluded that evidence has shown the feasibility of using pedometers with preschool children. 
There is very limited research on the physical activity of preschool children. As stated by Hay and Cairney (2006), the activity measurement of preschoolage children is virtually unaddressed. Therefore, the present study attempted to fill in the knowledge gap by investigating the activity levels of very young children. The purpose of the study was to determine the agreement of physical activity levels of Hong Kong 5- and 6-yearsold children as reflected by parent proxy report by HAES and another objective measurement of the young children's physical activity as recorded by the pedometer.

In the study, physical activity is referred to the movement of human body that results in energy expenditure at different levels above the resting metabolic rate (Anshel et al., 1991). The proxy report is referred to the report that was completed by the children's parents and it is used to assess activity of children too young to report their own behavior (Sallis, 1991).

\section{Preschool-Age Children in Hong Kong}

Over $90 \%$ of preschool children aged 3 to 6 years old attend preschools in Hong Kong in the last ten years (Hong Kong Government Census and Statistics Department, 2006). In 2008-2009, the total number of children attending preschool was over 137,000 . Of the limited research on preschools' activity levels in Hong Kong, Louie and Chan (2003) reported lower PA levels of preschoolers during playtime in preschools of smaller play area when compared with one of larger outdoor play area. Why are Hong Kong children physically inactive? Louie and Chan (2003) suggested the following reasons explaining Hong Kong children being physically inactive are less time spent at outdoor, little play space of children and over-concerned with children by teachers restraining their running speed and modes of play to avoid injuries.

\section{Methods}

\section{Sample}

Thirty children (15 boys, 15 girls) were randomly selected in upper classes of a preschool that is located in a public residential estate of the Hong Kong Island. The preschool was run by a non-government organization. Information provided by the principal of the preschool indicated that the majority of children came from families of lower to lower-middle social class background.

\section{Date Collection}

Proxy-report and electronic pedometers were used for the data collection in this study. All parents of the selected preschool children completed the HAES in a week before collection of children's pedometry data. Each parent was asked to choose a typical weekday and weekend to recall the child's physical activity levels and provide time the child waking up in the morning, sleeping at night, and taking naps during the pedometer data collection period. The HAES proxy-report contains dividing a day into four time periods as wake-up to (before) breakfast, (after) breakfast to (before) lunch, (after) lunch to (before) dinner, and (after) dinner to bedtime (Hay \& Cairney, 2006). In each time period, parents estimate and classify the percentage of children's physical activity levels into four different levels, which are inactive (e.g. lying down), somewhat inactive (e.g. sitting), somewhat active (e.g. walking) and very active (e.g. running). Also, parents choose one physical activity level from six different activity levels which can perfectly describe their children's overall activity level on one typical weekday and weekend, which are very inactive, inactive, somewhat inactive, somewhat active, active and very active. Then, parents determine if there is any difference of the children's physical activity levels and life patterns on this typical weekday and weekend when compared to the last six months. Finally, parents provide their work status, the daily average time being in contact with their children and their perceived degree of understanding of the children's daily activity levels.

Data collection of pedometry data involved daily step counts of four consecutive days starting either Thursday morning to Monday morning or Thursday afternoon to Monday afternoon. At the beginning of a preschool day on Thursday, each selected child was helped to wear a belt tightly fit onto the waist. Pedometer "SW-700" (Yamax, Jayan) was clipped onto the belt that was placed in line to the mid-point of the child's right thigh. The child was told to wear the belt during waking hours except bathing, swimming and sleeping consecutively from Thursday to Monday. The step reading shown by the pedometer was recorded every night by the parent just before his/her child going to bed. 


\section{Data Analysis}

The statistical data were analyzed by the Statistical Package for Social Science Version 11.0 (SPSS 11.0). Descriptive statistics of mean, standard deviation and frequencies of the children's physical activity data were computed.

For the HAES data, the percentage of time the child engaged in "somewhat active" and "active" activities during either weekday or weekend were converted to the percentage of time engaged in moderate-to-vigorous physical activity (MVPA) as scaled by the total minutes of non-sleeping time. Therefore, the dependent measure of the HAES data was the MVPA\% for weekday and weekend. The dependent measure of the pedometer data was the mean step count during weekday and weekend. The 2X2 ANOVA with an independent factor of gender and a repeated factor of day (weekday vs. weekend) was calculated for the HAES data and pedometer data. The agreement between the parent proxy report of the children's MVPA\% and the mean step count was determined by the Pearson product-moment correlation ( $\underline{\mathrm{r}})$ separately for weekday and weekend.

\section{Results}

The sample consisted of 15 boys and 15 girls randomly selected from four upper classes of a preschool. Due to the missing data collected from seven children because parents forgot to complete the pedometer record, final data analysis involved 12 boys and 11 girls. There were 9 boys and 4 girls from the morning session, 2 boys and 2 girls from the afternoon session and 1 boy and 5 girls from the whole day session.

\section{Parents Reporting Mean \% Time in Different Activity Levels}

The descriptive statistics of the parent proxy report showed that parents perceived the mean $\%$ of time their children's overall level of activity being active (42\%) and somewhat active (29\%) on a typical weekday. Furthermore, most parents perceived the mean percentage of time their children's overall level of activity were active (63\%) and somewhat active (29\%) on a typical weekend.

On a typical weekday, parents rated the highest \% of time children engaged in somewhat inactive activities for three out of the four segments of time (ranged from 42-51\%) (see Figure 1). The exception was lunch to dinner period that parents perceived their children spending highest \% of time (34\%) being engaged in very active activities. On a typical weekend, parents also rated the highest $\%$ of time children engaged in somewhat inactive activities during wake-up to breakfast (49\%) and dinner to bedtime $(44 \%)$ periods and children also engaged in very active activities during lunch to dinner period (35\%) (see Figure 2). The only difference between activity pattern during weekend and weekday was that parents rated highest $\%$ of time children engaged in somewhat active activities at breakfast to lunch period (43\%) on weekend, as opposed to somewhat inactive activities (41\%) and somewhat active activities (33\%) during the same period on weekday.

\section{Mean Daily Step Counts of Children on a Typical Weekday and Weekend}

The means of daily step counts of children on a weekday and weekend were shown in Table 1. It was found that the children's mean step count on weekend was more than weekday. Also, the mean step count of boys was more than girls on weekend but it was less than girls on weekday.

Table 1. Mean Step Count of Children (per day and per minute) on Weekday and Weekend.

\begin{tabular}{lllll}
\hline & \multicolumn{2}{c}{ Weekday } & \multicolumn{2}{c}{ Weekend } \\
\hline & Mean & Mean & Mean & Mean \\
& Step/day & Step/min & Step/day & Step/min \\
All $(n=23)$ & 6973 & 9.22 & 8341 & 11.29 \\
Boys $(n=12)$ & 6779 & 8.9 & 9791 & 12.9 \\
Girls $(n=11)$ & 7167 & 9.53 & 6890 & 9.64 \\
& & & & \\
\hline
\end{tabular}


Figure 1. Mean Percentage Time Parents' Rating Their Children's Overall Levels of Activity on One Typical Weekday.

Parent's estimation of their children's activity level in different periods of time on one typical weekday

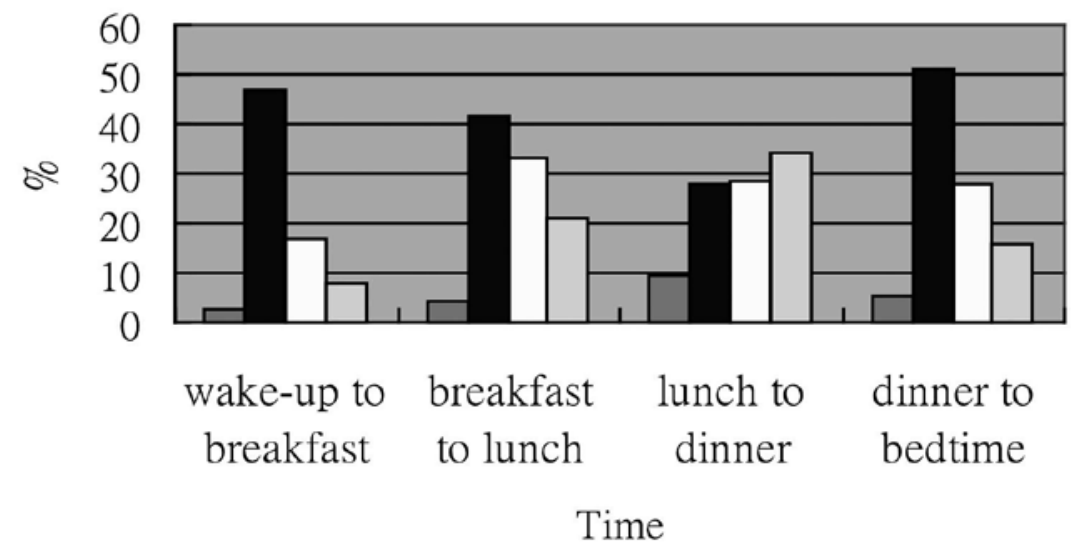

Inactve Somewhat inactive $\square$ Somewhat active $\square$ Very active

Figure 2. Mean Percentage Time Parents' Rating Their Children's Overall Levels of Activitiy in One Typical Weekend.

Parent's estimation of their children's activity level in different periods of time on one typical weekend

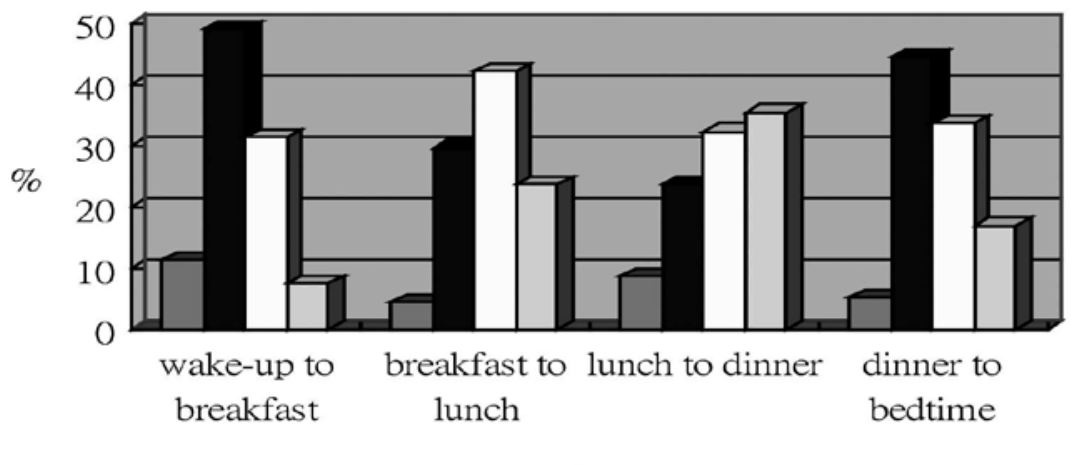

Time

Inactve $\square$ Somewhat inactive $\square$ Somewhat active $\square$ Very active 
Mean Percentage of Time in Moderate-to-Vigorous Physical Activity

The means of children's MVPA\% as reported by parents of the HAES on a weekday and weekend were contained in Table 2. The results showed that the mean
MVPA\% on weekend was higher than on weekday. Also, the means of boys' mean MVPA\% was higher than girls on both weekday and weekend.

Table 2. Mean \% MVPA and Mean Waking Hours on Weekday and Weekend.

\begin{tabular}{llllll}
\hline & \multicolumn{3}{c}{ Weekday } & \multicolumn{2}{c}{ Weekend } \\
\hline & $\mathrm{N}$ & \multicolumn{1}{l}{ Mean \% } \\
& MVPA & Waking Hours & Mean \% MVPA & Waking Hours \\
All children & 23 & $50.34 \pm 13.62$ & $14.11 \pm 0.82$ & $55.30 \pm 14.47$ & $13.72 \pm 0.72$ \\
Boys & 12 & $52.21 \pm 12.28$ & $14.19 \pm 0.57$ & $56.26 \pm 11.40$ & $13.69 \pm 0.47$ \\
Girls & 11 & $48.31 \pm 15.29$ & $14.03 \pm 1.04$ & $54.26 \pm 17.76$ & $13.75 \pm 0.96$ \\
\hline
\end{tabular}

\section{Effect of Gender by Weekday/Weekend as Repeated Factor for Pedometer \& HAES}

$2 \times 2$ ANOVA of gender by day (day as a repeated factor) was computed. For the pedometer data. No day difference $(\mathrm{F}=1.57, \mathrm{p}=0.22)$ and no gender difference $(\mathrm{F}=0.20, \mathrm{p}=0.66)$ was found. However, for the HAES data, parents reported higher MVPA\% on weekend than on weekdays $(\mathrm{F}=5.38, \mathrm{p}=0.03)$ and there was no gender difference $(\mathrm{F}=0.28, \mathrm{p}=0.60)$ on the parent report of MVPA\%. Because there was no gender difference for both pedometer and HAES data, subsequent data analyses were conducted for all children.

The relationship between the parent report of the percentage of time children engaged in MVPA and the daily step counts of children (per minute) on weekday and weekend were computed by the Pearson productmoment correlation (r). No significant correlation between these two activity data was found (weekday: $r=-0.33, p$ $=0.13$, weekend: $r=0.17, p=0.44)$.

\section{Discussions}

In this study, the HAES was used to determine the physical activity levels of five- to six-years-old children, which was estimated by parent report of their children's activity levels on one typical weekday and weekend. The pedometer readings were used to collect the step counts of children on two weekdays and weekend. In order to investigate the validity of the HAES proxy report, the parents' estimation on their children's percentage of time engaged in MVPA was used to correlate with the daily step counts of pedometer. However, the result showed that the relationship between the pedometer reading (daily mean step count per minute) and MVPA\% was not significantly correlated on both weekday and weekend. For example, in the HAES, most parents reported that their children were physically somewhat active and the MVPA\% of their children was high on weekdays and weekends; however, the pedometer data showed that the daily step counts of their children were quite low when compared with other studies. The children in this study had an average of 6,973 steps per day on weekdays and 8,341 steps per day on weekend. Comparing to a larger scale study using Yamax pedometers for measuring physical activity of 176 preschool children (Sigmund, Sigmundova, \& Ansari, 2009) with boys and girls taking a range of 9,923 steps to 11,864 steps per day, Hong Kong preschool children were much inactive.

There were several reasons that can explain the conclusion that parent report of MVPA\% in the HAES was not related to the pedometer data. Firstly, Hay and Cairney (2006) stated that HAES is weighted toward utility rather than accuracy. It was because there is no means to convert the intensity or hours of the HAES into physiological units to determine energy expenditure (Hay \& Cairney, 2006), the HAES can only provide estimation. Therefore it lacks precision so that small or subtle changes in activity will be missed due to the impossible fine-grained comparisons (Hay \& Cairney, 2006). Secondly, the HAES requires some basic mathematical and language proficiency for completion that may make the scale 
challenging for a small segment of the population (Hay \& Cairney, 2006). Thirdly, parents' observation on their children's physical activity patterns may not be accurate. Parents may not have enough time to observe their children since some have full-time employment. Although most parents believed that they were considerably clear or very clear about their children's physical activity level, there were still 10 out of 24 parents who are fulltime and part time workers, so they may not have much time staying at home and observe their children's physical activity patterns. Another possible reason is that young children's activities are often of short bursts, are intermittent and vigorous in nature. These characteristics may make it hard for parent to form a clear understanding about the amount and level of activities that his/her child has in a day. Furthermore, although a large part of the parents are householders (11 out of 24) who have more time in contact with their children, they, in fact, may not observe their children every minute. In particular, parents may not know the physical activity levels of children during school time on weekdays.

Besides, there is a common misconception among parents and teachers that young children are much more active than indicated by the research data (Pate et al., 2008). O'Connor and Temple (2005) concluded that parents think their children are highly active while in preschool or daycare. However researchers indicated that children who attend preschools spend 30 hours per week at school with 25 hours of the time being spent on sedentary activities and less than 1 hour being spent on MVPA (Pate et al., 2008). This manifests that parents might think that they were very clear the physical activity level of their children but their perceptions may not be accurate.

On the other hand, the accuracy of pedometer may influence the result of this study. Although many researches indicated that pedometer was a valid and reliable measure of children's physical activity (Hands, Parker, \& Larkin, 2006; Louie \& Chan, 2003), the result of this study showed that there is no significant relationship between daily step counts and the physical activity levels of children in HAES parent proxy report. As stated by researchers, pedometers fail to measure slow walking speeds or upper body movements, and most are unable to $\log$ data to determine changes in exercise intensity (Macfarlane, Lee, Ho, Chan, \& Chan, 2006). This drawback of the pedometer is the limitation of the study. Additionally, when compared pedometer with indirect calorimetry, the pedometer underestimated energy expenditure which suggested that pedometers provide accurate measurements for walking speeds from 3-4 mph but are less accurate at slower speeds (Strycker, Duncan, Chaumeton, Duncan \& Toobert , 2007). Another research also indicated that pedometers are unable to measure intensity of activity or to accurately record some common activities in young children such as cycling or skateboarding. These may affect the validity of the information gathered with young children given the episodic and variable nature of their play (Strycker et al., 2007).

Another reason to explain why there is no significant relationship between pedometer readings and children's physical activity level is that pedometers may appear to be a motivation tool for children in prompting them to be more physically active. According to the study of Jackson and Howton (2008), participants of the study reported that wearing the pedometer influenced their overall activity participation. These subjective responses from the questionnaire supported the increase in the number of steps reported throughout the 12-week intervention period. Moreover, in another research done by Clarke et al (2007), the effectiveness of a pedometer program for increasing physical activity levels and reducing body weight in overweight and obese mothers of young children was tested. The result showed a positive relationship between the pedometer program with mothers' motivational readiness to exercise, exercise self-efficacy, pedometer steps, and pedometer kilocalories (Clarke et al, 2007). Therefore, children may be more active than before the study due to the activator function of pedometer, leading to the inaccurate results found.

Parents reported higher MVPA\% of their children's activities during weekends than weekdays. Sigmund, Croix, Miklankova, and Fromel (2007) stated that although preschoolers showed similarities in physical activity levels between weekdays and weekends, the physical activity on weekend is higher than on school days. They further explained that preschool children are physically active regardless of the type of day and daily regime may be attributed to the fact that preschool children cannot distinguish between school time and free time. Although the daily program in preschools definitely provides more opportunities to perform physical activity, preschools also have long periods of physical inactive activities, including 
lying or sleeping for $60 \mathrm{~min}$ after lunch every day and time spent sitting during a morning snack break (10-20 $\mathrm{min})$, lunch (15-30 $\mathrm{min})$ and afternoon snack break (10-20 min) (Sigmund et al., 2007).

In addition, the study of Pate et al. (2008) manifested that space constraints, lack of equipment for physical activity, and lack of scheduled times for free play and outdoor play may be important influencing factors of children's physical activity levels. And it is shown that being outdoors is one of the most significant correlates of physical activity in children. Louie and Chan (2003) explained the factors that Hong Kong children being physically inactive are spent less time outdoors, little playing space for children in school time and overconcerned with children by teachers restraining children's running speed and modes of play to avoid injuries on weekdays. Studying in classrooms and spending less time outdoors are common practice in preschools in Hong Kong.

All in all, in this study, although the selected children attending the preschool in this study have free activity time during preschool days but they just play in a small indoor area, making the children's physical activity level being lower on weekdays than weekend. Also, children need to follow the instructions by the teacher during school time, for instance, they cannot run in the classroom, they need to sit down and cannot leave their seat without teacher's permission. So, Hong Kong children may not be active during preschool time on weekdays when compared with weekend.

Furthermore, parents play an important role for children which can affect their physical activity level too. Research conducted by Pate et al. (2008) showed that parents thought that their children are highly active in preschool or daycare, thus parents may be less likely to provide opportunities or encourage physical activity behaviors in other settings, leading to the reduced levels of activity during the whole weekdays.

Although there is no significant mean difference between boys' and girls' step counts on both weekdays and weekend, the mean step counts (per minute) of boys have 3.3 steps per minute more than girls' on weekend with similar step counts on weekdays. So, it can be concluded that boys were little bit more active than girls on weekend. Louie and Chan (2003) found that boys spent more time involved in vigorous and very vigorous activity than girls. They have also found that boys were more involved in rough-and-tumble play than girls (Louie \& Chan, 2003), so it is not surprising that boys were more active than girls on both weekdays and weekend.

There are a few limitations of this study. Because only 24 preschool children participated in the study, research generalization of findings to the larger population is not possible. Due to the time constraint, some factors which need a longer observation time were not examined in this study. For instance, free play space at the preschool, family health related background, as well as the lifestyles of parents were not examined. Also, the testing period should be longer to increase the validity of HAES. Furthermore, the test should be implemented with two or more measurements when testing the validity of HAES proxy report. Researchers suggested using a combination of objective monitoring and direct observation may provide the best standard for the assessment of physical activity measurement tools (Oliver, Schofield, \& Kolt, 2007).

\section{References}

Anshel, M. H., Freedson, P., Hammill, J., Haywood, K., Hoyvat, M., \& Plowman, S. A. (1991). Dictionary of the sport and exercise sciences. Champaign, IL: Human Kinetics.

Armstrong, N., \& Welsman, J. (1997). Young people and physical activity. Oxford: Oxford University Press.

Berlin, J. E., Storti, K. L., \& Brach, J. S. (2006). Using activity monitors to measure physical activity in freeliving conditions. Physical Therapy, 86, 1137-1145.

Blue Cross and Blue Shield Association. Target heart rate for children [Data file]. Retrieved April 20, 2009, from http://www.horizon-bcbsnj.com/shapeitup/ siu_heart_rate.asp

Cardon, G.M., \& De Bourdeaudhuij, 1.M.M. (2008). Are preschool children active enough? Objectively measured physical activity levels. Research Quarterly for Exercise and Sport, 79, 326-332.

Chan, C. M. S. (2009). Obesity among kindergarten children in Hong Kong [abstract]. China International Academic Congress on Obesity (CIACO), 24-26, February, 2009, Beijing, China. 
Chow, B.C. (2008). Convergent validity of the electronic pedometer with the TriTrac RT3 accelerometer for measuring structured play activities in preschool children. Journal of Bio-Education, 3(1), 46-54.

Clarke, K. K., Freeland-Graves, J., Klohe-Lehman, D. M., \& Milani, T. J., et al. (2007). Promotion of physical activity in low-income mothers using pedometers. [Abstract]. Journal of the American Dietetic Association, 107 (6), 962-967. Abstract retrieved April 20, 2009, from ProQuest database.

Corder, K., Ekelund, U., Steele, R. M., Wareham, N. J., \& Brage, S. (2008). [Abstract]. Assessment of physical activity in youth. Journal of Applied Physiology, 105 (3), 977. Abstract retrieved April 20, 2009, from ProQuest database.

Dwyer, G.M., Higgs, J., Hardy, L. L., \& Baur, L. A. (2008). What do parents and preschool staff tell us about young children's physical activity: a qualitative study. [Abstract]. International Journal of Behavioral Nutrition and Physical Activity, 5, 66. Abstract retrieved April 20, 2009, from ProQuest database.

Gavarry, O., Giacomoni, M., Bernard, T., Seymat, M., \& Galgairette, G. (2003). Habitual physical activity in children and adolescents during school and free days. Medicine \& Science in Sports and Exercise, 35(3), $525-531$

Grontved, A., Pedersen, G.S., Anderson L.B. et al. (2009). Personal characteristics and demographic factors associated with objectively measured physical activity in children attending preschool. Pediatric Exercise Science, 21, 209-219.

Hay, J.A., \& Atkinson, S., \& Halton, J. (1995). An examination of the reliability of the Habitual Activity Estimation Scale (HAES). In Proceedings of the Pediatric Work Physiology Symposium, 49.

Hay, J. A., \& Cairney, J. (2006). Development of the habitual activity estimation scale for clinical research: A systematic approach. Pediatric Exercise Science, 18, 193-202.
Hay, J.A., Faught, B.E., Cairney, J., \& Wade, T.L. (2005). Parental reports of children's activity-What are they really reporting ? Pediatric Exercise Science, 17, 99.

Hands, B., Parker, H., \& Larkin, D. (2006). Physical activity measurement methods for young children: A comparative study. Measurement in Physical Education and Exercise Science, 10(3), 203-214.

Hinkey, T., Crawsford, D., Salmon, J., Okely, A.D., \& Hesketh, K. (2008). Preschool children and physical activity: A review of correlates. American Journal of Preventive Medicine, 34, 435-441.

Hong Kong Government Census \& Statistics Department (2006). Hong Kong 2006 population by-census main report (on page 18). Retrieved from: http://www.censtatd.gov.hk/ products_and_services/products/publications/statistical_ report/population_and_vital_events/index_cd_B1120047_ dt_latest.jsp

Hong Kong Government Department of Health, Student Health Service (2009). Statistics on obesity rate of school children. Available at: http://www.studenthealth. gov.hk

Jozefiak, T., Larsson, B., Wichstrøm, L., Mattejat, F., \& Ravens-Sieverer, U. (2008). Quality of life as reported by school children and their parents: a cross-sectional survey. Health and Quality of Life Outcomes, 6(34), 1-11.

Jackson, D.M., Reilly, J.J., Kelly, L.A., Montgomery, C., Grant, S., \& Paton, J.Y. (2003). Objectively measured physical activity in a representative sample of 3- to 4-year-old children. Obesity Research, 11, 420-425.

Jackson, E. M., Howton, A. (2008). Increasing walking in college students using a pedometer intervention: Differences according to body mass index. Journal of American College Health, 57(2), 159-164.

Lobstein, T., Baur, L., \& Uauy, R. (2004). Obesity in children and young people : a crisis in public health. Obesity Review, 5, 4-85.

Louie, L., \& Chan, L. (2003). The use of pedometry to evaluate the physical activity levels among preschool children in Hong Kong. Early Child Development and Care, 173(1), 97-107. 
Macfarlane, D.J., Lee, C. C. Y., Ho, E.Y. K., Chan, K. L., \& Chan, D. (2006). Convergent validity of six methods to assess physical activity in daily life. Journal of Applied Physiology, 101, 1328-1334.

Molgaard, C., Thomsen, B.L., \& Michaelkson, K.F. (2001). The influence of calcium intake and physical activity on bone mineral content and bone size in healthy children and adolescents. Osteoporosis International,12, 887-894.

O'Connor, J. P., \& Temple, V. A. (2005). Constraints and facilitators for physical activity in family day care. Australia Journal Early Child, 30 (4), 1-9.

Ogden, C.L., Carroll, M.D., Curtin, L.R., McDowell, M.A., Tabak, C.J., \& Flegal, K.M. (2006). Prevalence of overweight and obesity among US children, adolescents, and adults. JAMA, 291, 2847-2850.

Oliver, M., Schofield, G. M., \& Kolt, G.S. (2007). Physical activity in preschoolers: Understanding prevalence and measurement issues. Sports Medicine, 37(12), 1045-1070.

Pate, R.R., Pfeiffer, K.A., Trost, S.G., Ziegler, \& P., Dowda, M. (2004). Physical activity among children attending preschools. Pediatrics, 114, 1258-1263.

Pate, R. R., McIver, K., Dowda, M., Brown, W. H., Addy, C. (2008). Directly observed physical activity levels in preschool children. The Journal of School Health, 78 (8), 438-444.

Riddoch, C.J., \& Boreham, C. (2000). Physical activity, physical fitness, and children's health: current concepts. In N. Armstrong \& W. van Wechelen (Eds.), Pediatric exercise science and medicine (pp. 243251). Oxford: Oxford University Press.

Riddoch, C.J., \& Boreham, C. (2004). Physical activity, physical fitness, and children's health: current concepts. In N. Armstrong \& W. van Wechelen (Eds.), Pediatric exercise science and medicine (pp. 243251). Oxford: Oxford University Press.

Sallis, J. F. (1991). Self-report measure of children's physical activity. Journal of School Health, 61(5), 215-219.
Sirard, J.R., \& Pate, R. R. (2001). Physical activity assessment in children and adolescents. Sports Medicine, 31(6), 439-454.

Strycker, L. A., Duncan, S. C., Chaumeton, N. R., Duncan, T. E., \& Toobert, D. J. (2007). Reliability of pedometer data in samples of youth and older women. International Journal of Behavioral Nutrition and Physical Activity, 4(4), 1-8.

Sigmund, E., Croix, M. D. S., Miklankova, L., \& Fromel, K. (2007). Physical activity patterns of kindergarten children in comparison to teenagers and young adults. European Journal of Public Health, 17 (6), 646-651.

Spurrier, N. J., Magarey, A. A., Golley, R., Curnow, F., \& Sawyer, M. G. (2008). Relationships between the home environment and physical activity and dietary patterns of preschool children: a cross-sectional study. [Abstract]. International Journal of Behavioral Nutrition and Physical Activity, 5, 31. Abstract retrieved April 20, 2009, from ProQuest database.

U.S. Department of Health Human Services [USDHHS]. (2000). Healthy People 2010 (Conference edition). Washington, DC: U.S. Department of Health and Human Services.

Varni, J. W., Limbers, C. A., \& Burwinkle, T. M. (2007). Parent proxy-report of their children's healthrelated quality of life: an analysis of 13,878 parents' reliability and validity across age subgroups using the PedsQL ${ }^{\text {тм }} 4.0$ Generic Core Scales. Health and Quality of Life Outcomes, 5(2), 1-10.

\section{Correspondence}

\section{Prof. Bik Chow}

Department of Physical Education, Hong Kong Baptist University,

Kowloon Tong,

Kowloon, HONG KONG.

Email: bchow@hkbu.edu.hk 